\title{
What to Do with Toxic, Contaminated Cellulose-based Adsorbents
}

\author{
Martin A. Hubbe \\ This editorial considers the end fates of toxic materials, such as heavy \\ metals, dyes, and synthetic organic compounds, which can be recovered \\ from polluted water by using bio-based adsorbents. The point of the \\ editorial is that insufficient research attention has been paid to the final \\ fate of such contaminants. By contrast, much is known regarding factors \\ affecting the adsorption capacities and rates of adsorption onto cellulose- \\ based materials. Highly contaminated solutions are produced during the \\ regeneration of biosorbent materials. Eutectic freeze crystallization \\ potentially could be used to isolate relative pure compounds of heavy \\ metals from such solutions. Alternatively, biochar can be prepared from \\ cellulosic material in such a way as to achieve strong attachment to certain \\ pollutants. Such biochar, after its use as an adsorbent, could be placed in \\ the ground, where it can be expected to remain stable as sequestered \\ carbon. A high ion exchange capacity of such biochar has potential to \\ reduce the rates of leaching, which could otherwise lead to contamination \\ of groundwater near to landfill sites. As shown by these examples, some \\ promising answers to the final fate of contaminants may conform to a \\ "circular economy" model, whereas other promising answers may conform \\ to a "cradle-to-grave" viewpoint.
}

Keywords: Spent biosorbents; Toxic adsorbates; Landfilling; Metals; Dyes; Organic compounds

Contact information: North Carolina State University, Department of Forest Biomaterials, Campus Box 8005, Raleigh, NC 27695-8005; Email: hubbe@ncsu.edu

\section{Biosorption of Pollutants - An Incomplete Answer}

Cellulose-derived adsorbent materials are often proposed as a promising option to remove pollutants from contaminated water. Although there are countless published articles documenting the success of such adsorption strategies (see Hubbe et al. 2011, 2012, 2013 , 2014), the ultimate fate of the contaminants is seldom addressed in the published articles. Some authors document the regeneration of biomass-based adsorbent materials, for instance by exposing them to a salty brine or low $\mathrm{pH}$ water, etc., thus causing the pollutant, e.g. a heavy metal ion or a dye, to be released. However, such procedures merely place the pollutant back into an aqueous solution, leaving the ultimate fate of the pollutant still unresolved.

It is proposed here that more research attention needs to be paid to identifying and perfecting promising strategies related to the final fate of such pollutants as heavy metals, synthetic dyes, and toxic organic compounds. Such work can be expected to face great challenges. In typical cases, the contaminated cellulose-based adsorbent will contain too much water to be suitable for landfilling, which in any case would involve concerns about leaching of the contaminants into groundwater. Many districts have prohibitions against the use of incineration as a means of dealing with strongly metal-contaminated materials (Linak and Wendt 1993). 


\section{Used Biosorbents Loaded with Organic Contaminants}

In the case of organic contaminants, one of the key routes to consider is biological degradation. This can involve such options as composting, or even conventional secondary wastewater treatment with the use of aeration and activated sludge. Another option, though conflicting with a point made in the previous paragraph, may be incineration. To deal with hard-to-degrade organic compounds such as lignin decomposition products and other phenols, advanced oxidation strategies such as ozone, Fenton oxidation, or $\mathrm{TiO}_{2}$-catalyzed UV irradiation, can be carried out as pretreatments before biodegradation steps (Hubbe et al. 2016).

High-temperature pressurized treatment, i.e. hydrothermal treatment, can be another way to break down organic chemicals and render the mixture for suitable for biodegradation as a means to decrease the biological oxygen demand (BOD) and toxicity of the treated water. Hydrothermal processing, because it does not require a phase change of the water present in a contaminated material, represents a relatively low-energy way to break down recalcitrant organic compounds. By the use of pressurized conditions, boiling is suppressed, while at the same time the temperature becomes high enough so that the molecules frequently reach various transition states related to their potential decomposition into benign and more readily biodegradable forms (Kruse et al. 2013). The treated mixture then can be used to generate and collect a higher amount of methane, which has value as a fuel, in a subsequent anaerobic digestion step (Pages-Diaz et al. 2020).

\section{Used Biosorbents Loaded with Heavy Metals}

When metals are the main contaminant in cellulose-based adsorbents, after their use, research is needed to find the most promising way to convert various brine concentrates, often obtained in the course of regeneration of the adsorbent materials, back to isolated compounds, which might have potential value. In principle, this can be accomplished by a process called eutectic freeze crystallization (EFC) (Randall et al. 2011; Hubbe et al. 2018). Though EFC has been demonstrated as an effective and energyefficient method, the amount of published work is relatively little. It is known, for instance, that certain inorganic compounds can be separated from each other, as solid materials, by careful application of ERC in stages and different temperatures. The purity can be increased by adding seed crystals (Aspeling et al. 2020). However, it has not been shown yet that EFC can be applied to complex mixtures that contain multiple dissolved metal species as well as other contaminants.

\section{A Stretch Goal to Recover Each Contaminant in Pure Form}

Visionaries have proposed usage or the term "circular economy" to describe a world in which humans can thrive for many years without damaging the biosphere or depleting the resources. Part of such a system would require ways to re-use even the most dilute and toxic components of the byproducts and wastes of the many unit processes that together make up the technology that supports us in our daily lives. Much attention has been paid to some steps that are needed in creating a circular economy, such as adsorbing contaminants from water, by the use of cellulose-derived adsorbent materials. However, the work cannot be regarded as being complete. Difficult steps remain to be resolved regarding the final fate of toxic substances such as heavy metals, dyes, and other recalcitrant compounds that become collected onto such adsorbents as biomass, biochar, and lignocellulose-derived activated carbon. 


\section{A Fallback Goal to Hold Contaminants So That They Do No Harm}

When practitioners of Life Cycle Assessment set out to do a comprehensive analysis, the term "cradle-to-grave" is often employed. In order for that term to be valid, the end state must indeed represent a stable condition, without significant further harm to the environment continuing. For instance, two kinds of harm can be expected if a contaminated biomass-based adsorbent is merely buried in the ground. On the one hand, most plant-based materials are likely to decay anaerobically in the buried environment, which may be moist and airless. Such decay will likely result in evolution of methane gas, thereby contributing to global warming if it is not completely collected (Bolan et al. 2013). Meanwhile, leaching may lead to contamination of groundwater with heavy metal ions or with toxic organic compounds. It turns out that both of these problems can be addressed. By pyrolysis of biomass at temperatures in the range from about 500 to $800{ }^{\circ} \mathrm{C}$, for optimized times, the material can be converted to biochar. Such conversion tends to increase the hydrophobic character of the material, which can lead to stronger association with some organic contaminants of concern, such as phenols (Oh and Seo 2016; Komnitsas and Zaharaki 2016). By adjusting the conditions of pyrolysis, it is also possible to increase the ion exchange capacity, so that the resulting biochar holds more tightly onto the metal ions (Ahmad et al. 2014). Biochar has the further advantage of being quite stable to further biodegradation, so that it generally is not associated with methane generation, and it sequesters carbon (Mukherjee and Lal 2013). So in cases where procedures associated with a true circular economy have not yet been demonstrated, an optimized cradle-tograve" strategy may be regarded as the next best thing.

\section{References Cited}

Ahmad, M., Rajapaksha, A. U., Lim, J. E., Zhang, M., Bolan, N., Mohan, D., Vithanage, M., Lee, S. S., and Ok, Y. S. (2014). "Biochar as a sorbent for contaminant management in soil and water: A review," Chemosphere 99, 19-33. DOI: 10.1016/j.chemosphere.2013.10.071

Aspeling, B. J., Chivavava, J., and Lewis, A. E. (2020). "Selective salt crystallization from a seeded ternary eutectic system in eutectic freeze crystallization," Separ. Purif. Technol. 248, article no. 117019. DOI: 10.1016/j.seppur.2020.117019

Bolan, N. S., Thangarajan, R., Seshadri, B., Jena, U., Das, K. C., Wang, H., and Naidu, R. (2013). "Landfills as a biorefinery to produce biomass and capture biogas," Bioresour. Technol. 135, 578-587. DOI: 10.1016/j.biortech.2012.08.135

Hubbe, M. A., Becheleni, E. M. A., Lewis, A. E., Peters, E. M., Gan, W., Nong, G., Mandal, S., and Shi, S. Q. (2018). "Recovery of inorganic compounds from spent alkaline pulping liquor by eutectic freeze crystallization and supporting unit operations: A Review," BioResources 13(4), 9180-9219. DOI: 10.15376/biores.13.4.Hubbe

Hubbe, M. A., Beck, K. R., O'Neal, W. G., and Sharma, Y. C. (2012). "Cellulosic substrates for removal of pollutants from aqueous systems: A review. 2. Dyes," BioResources 7(2), 2592-2687. DOI: 10.15376/biores.7.2.2592-2687

Hubbe, M. A., Hasan, S. H., and Ducoste, J. J. (2011). "Cellulosic substrates for removal of pollutants from aqueous systems: A review. 1. Metals," BioResources 6(2), 21612287. DOI: $10.15376 /$ biores.6.2.2161-2287 
Hubbe, M. A., Metts, J. R., Hermosilla, D., Blanco, M. A., Yerushalmi, L., Haghighat, F., Lindholm-Lehto, P., Khodaparast, Z., Kamali, M., and Elliott, A. (2016).

"Wastewater treatment and reclamation: A review of pulp and paper industry practices and opportunities," BioResources 11(3), 7953-8091. DOI: 10.15376/biores.11.3.Hubbe

Hubbe, M. A., Park, J., and Park, S. (2014). "Cellulosic substrates for removal of pollutants from aqueous systems: A review. Part 4. Dissolved petrochemical compounds," BioResources 9(4), 7782-7925. DOI: 10.15376/biores.9.4.7782-7925

Hubbe, M. A., Rojas, O. J., Fingas, M., and Gupta, B. S. (2013). “Cellulosic substrates for removal of pollutants from aqueous systems: A Review. 3. Spilled oil and emulsified organic liquids," BioResources 8(2), 3038-3097. DOI: 10.15376/biores.8.2.3038-3097

Komnitsas, K. A., and Zaharaki, D. (2016). "Morphology of modified biochar and its potential for phenol removal from aqueous solutions," Frontiers Environ. Sci. 4, article no. 26. DOI: 10.3389/fenvs.2016.00026

Kruse, A., Funke, A., and Titirici, M. M. (2013). "Hydrothermal conversion of biomass to fuels and energetic materials," Current Opin. Chem. Biol. 17(3), 515-521. DOI: 10.1016/j.cbpa.2013.05.004

Linak, W. P., and Wendt, J. O. L. (1993). "Toxic metal emissions from incineration mechanisms and control," Prog. Energy Combustion Sci. 19(2), 145-185. DOI: 10.1016/0360-1285(93)90014-6

Mukherjee, A., and Lal, R. (2013). "Biochar impacts on soil physical properties and greenhouse gas emissions," Agron.-Basel 3(2), 313-339. DOI: 10.3390/agronomy3020313

Oh, S.-Y., and Seo, Y. D. (2016). "Sorption of halogenated phenols and pharmaceuticals to biochar: Affecting factors and mechanisms," Environ. Sci. Pollut. Res. 23(2), 951961. DOI: $10.1007 / \mathrm{s} 11356-015-4201-8$

Pages-Diaz, J., Alvarado, A. O. C., Montalvo, S., Diaz-Robles, L., and Curio, C. H. (2020). "Anaerobic bio-methane potential of the liquors from hydrothermal carbonization of different lignocellulose biomasses," Renew. Energy 157, 182-189. DOI: $10.1016 /$ j.renene.2020.05.025

Randall, D. G., Nathoo, J., and Lewis, A. E. (2011). "A case study for treating a reverse osmosis brine using eutectic freeze crystallization - Approaching a zero waste process," Desalination 266, 256-262. DOI: 10.1016/j.desal.2010.08.034 